\title{
Enhancing Parenting Skills Among Nonresident African American Fathers as a Strategy for Preventing Youth Risky Behaviors
}

\author{
Cleopatra Howard Caldwell · Jane Rafferty • \\ Thomas M. Reischl • E. Hill De Loney • \\ Cassandra L. Brooks
}

Published online: 16 January 2010

(C) Society for Community Research and Action 2010

\begin{abstract}
This study evaluated the effectiveness of a theoretically based, culturally specific family intervention designed to prevent youth risky behaviors by influencing the parenting attitudes and behaviors of nonresident African American fathers and the parent-child interactions, intentions to avoid violence, and aggressive behaviors of their preadolescent sons. A sample of 158 intervention and 129 comparison group families participated. ANCOVA results indicated that the intervention was promising for enhancing parental monitoring, communication about sex, intentions to communicate, race-related socialization practices, and
\end{abstract}

A version of this paper was presented as part of the Fatherhood across the Life Cycle in Multiple Social Contexts Symposium at the Society for the Study of Human Development Meeting, The Pennsylvania State University, State College, PA, October 20, 2007.

\section{H. Caldwell ( $\square)$}

School of Public Health, University of Michigan,

109 Observatory Street, Ann Arbor, MI 48109-2029, USA

e-mail: cleoc@umich.edu

\section{J. Rafferty}

Program for Research on Black Americans, Research Center for Group Dynamics, Institute for Social Research, University of Michigan, Ann Arbor, MI, USA

\section{T. M. Reischl}

Prevention Research Center of Michigan, School of Public Health, University of Michigan, Ann Arbor, MI, USA

\section{E. H. De Loney}

Flint Odyssey House, 1225 Martin Luther King Drive, Flint, MI, USA

\section{L. Brooks}

Department of Psychiatry, Prevention Research Center of Michigan, School of Public Health, University of Michigan, Ann Arbor, MI, USA parenting skills satisfaction among fathers. The intervention was also beneficial for sons who reported more monitoring by their fathers, improved communication about sex, and increased intentions to avoid violence. The intervention was not effective in reducing aggressive behaviors among sons. Findings are discussed from a family support perspective, including the need to involve nonresident African American fathers in youth risky behavior prevention efforts.

Keywords African American families .

Fathers and sons - Nonresident fathers .

Parenting behaviors · Family interventions .

Community-based participatory research

\section{Introduction}

A number of risk factors have been associated with youth violent behavior, substance use, and early sexual initiation. These include early aggressive behavior, permissive attitudes toward risky behaviors, poor self-regulation, engaging in other risky behaviors, antisocial peers, living in poor neighborhoods, increased hormonal levels in males, lack of efficacy to delay risky behaviors, lack of family support, exposure to family conflict, inconsistent discipline, parental attitudes favorable toward risky behaviors, low parental involvement and living with a single-parent (Dittus et al. 1997; Henry et al. 2001; Herrenkohl et al. 2001; Kosterman et al. 2001; Paschall and Hubbard 1998; Thornberry et al. 1997). African American youth, especially males, have been exposed to and engage in violent behavior and early sexual initiation at higher rates than other adolescents. This puts them at risk for a number of poor health outcomes as adults (Alan Guttmacher Institute 2006; Blum et al. 2000).

Most preventive interventions designed to address youth risky behaviors have focused on increasing knowledge and 
changing the attitudes and behaviors of the youth (Thornton et al. 2002; USDHHS 2001). Interventions that only target the youth miss opportunities to affect change at larger environmental levels, which is critical for sustaining healthy lifestyles. A recent report by the National Center for Injury Prevention and Control (NCIPC; Thornton et al. 2002) established research priorities that called for developing and evaluating youth violence interventions at multiple levels, including the family, school, and community levels. With such an approach, a broader array of strategies can be used in preventing youth risky behaviors.

Previous studies provided support for involving mothers more extensively in youth preventive interventions (Brody et al. 2004; Dancy et al. 2006; DiIorio et al. 2006; Lefkowitz et al. 2000). Increasing developmental knowledge, reinforcing positive child behaviors by giving praise or offering privileges, showing adequate attention to discipline and monitoring, and effective communication were emphasized as critical components of these interventions. Recently, researchers have begun to examine the influence of father involvement on the health and well-being of their children. Both resident and nonresident fathers have been found to contribute to positive child outcomes, particularly when quality rather than quantity of time was considered (Coley and Medeiros 2007; Way and Gillman 2000). Studies of parenting interventions involving fathers typically target fathers of infants or young children, teenage fathers, or fathers of children with problems (Braver and Griffin 2000; Fagan and Stevenson 2002; Joshi and Battle 1990).

Interventions for fathers of preadolescents and adolescents rarely have been studied. The fact that so little attention has focused on interventions with these fathers is unfortunate because there are changes that occur during these developmental stages that have been associated with youth risky behaviors (Haugaard 2001). The NCIPC report (Thornton et al. 2002), for example, noted that aggression beliefs and tendencies to attribute hostile intent to others develop rapidly between ages 6 and 12; while DeLamater and Friedrich (2002) stressed that increased sexual awareness and sexual exploration occur during preadolescence, which they define as 8-12 years old. Thus, late childhood and preadolescence are ideal developmental periods for interventions aimed at preventing youth violence and early sexual debut. Understanding how fathers can be engaged in preventive interventions for their children during these developmental periods have implications for expanding current approaches to addressing youth risky behaviors.

This paper describes the results of an evaluation of a theoretically based, culturally specific intervention designed to involve nonresident African American fathers in the lives of their preadolescent sons in an effort to prevent youth violent behavior, substance use, and early sexual debut. Involving nonresident African American fathers in youth preventive interventions is advantageous for several reasons including providing an opportunity for fathers to learn more about the developmental needs of their sons and to develop effective parenting skills to assist their sons during adolescence. Interventions with nonresident fathers can provide opportunities for them to share insights about relationships, life challenges, and resources with other fathers that could be helpful after the intervention ended. We also thought that influencing the parenting and cultural knowledge, attitudes, and behaviors of nonresident African American fathers could be vital strategies for enhancing the family environment of African American boys.

\section{Parental Behaviors and Adolescent Risky Behaviors}

Findings from developmental research generally suggests that engaging in some form of aggressive behavior in childhood is relatively common; however, this aggression is expected to diminish as children learn more socially acceptable ways of handling pressure (Kosterman et al. 2001). The family, especially parents, is expected to socialize children to respond to environmental stressors in prosocial ways through nurturance and support to prevent or reduce aggressive acts as they mature. Socialization for substance use and sexual behavior also occurs within the family actively or by example. Three parenting behaviors consistently have been associated with less risky behavior in these areas for African American youth: (a) parental monitoring, (b) parental involvement (e.g., support, contact), and (c) parent-child communication. Empirical evidence presented below suggests that parent skill building in these areas may be useful in interventions aimed at multiple risky behaviors.

Parental monitoring has been associated with less violent behavior among African American youth (Griffin et al. 2000; Li et al. 2000); however, gender differences were evident. Consistent findings indicated that monitoring was more effective for females than for males, regardless of whether or not youth were part of single- or two-parent families (Griffin et al. 2000; Li et al. 2000). Griffin et al. (2000) also found that African American youth who engaged in violence perpetration and substance use were from families with low parental involvement and problematic parent-child communication.

Studies of nonresident father involvement and delinquency and youth violent behavior among African American youth revealed mixed results. Thomas et al. (1996), for example, found that African American males living with their mothers committed fewer delinquent acts if they had less involvement from their nonresident fathers. They measured delinquent acts as incorporating both non-violent (e.g., stealing, damaging property, having sex, forgery, and breaking and entering), and violent acts (e.g., assaults, gang fighting, and pushing or hitting a parent). Zimmerman et al. 
(1998) found that support from nonresident fathers helped African American male adolescents overcome risks associated with the negative influences of being around violent adults. Father support also was associated with less fighting behavior in this study. A longitudinal study of non-violent delinquency (e.g., stealing, damaging property, substance use, cheating in school and school detention) involving low-income, ethnically diverse families by Coley and Medeiros (2007) found that more non-resident father involvement prospectively predicted reductions in nonviolent delinquency among youth who initially exhibited highly delinquent behavior. They also found that father involvement increased as adolescents engaged in more delinquency, especially in African American families. These conflicting findings about the influences of nonresident father involvement on youth outcomes stem, in part, from conceptual and methodological differences across studies. Discrepancies in the meaning of father involvement, non-violent and violent delinquency and youth violence, as well as different study respondents contribute to the inconsistent findings. Clearly delineating the dimensions of father involvement examined (e.g., contact, support, communication), type of delinquency or violent behavior assessed (e.g., property damage or gang fighting), and study participants (e.g., adolescents, mothers, fathers, or multiple informants) in the research will be critical for accumulating evidence with implications for interventions with nonresident fathers.

With regard to parent-child communication, previous research has indicated that parents engaged in sex-related communication more frequently and with a wider range of sexual topics with daughters than with sons (Moore et al. 1986; Nolin and Peterson 1992). Moore et al. (1986) found that $17 \%$ of sons reported discussing sex with their parents compared to $67 \%$ of daughters. When sons did discuss sex they preferred to do so with their fathers. These studies did not include African American youth. Nevertheless, the findings are important for understanding issues related to parent-child communication about sex, especially with same-sex parent. Dittus et al. (1997) extended this work with African American youth by examining resident and nonresident fathers' attitudes about adolescent sexual debut. They found that perceived paternal disapproval was associated with delayed sexual debut, regardless of fathers' residential status. Thus, by communicating their disapproval, African American fathers may be influential in preventing early sexual debut among their children.

Parenting Interventions and Risky Behavior Among African American Youth

Wills et al. (2003) identified several mechanisms through which parental behaviors influenced youth risky behaviors in a recent intervention study of 297 rural African American families with early adolescents. Parental supportiveness influenced adolescent substance use and sexual debut indirectly through shaping self-control behaviors and defining social images of abstainers. Boys were at greater risk than girls for substance use and early sexual debut because they had less self-control and more unfavorable attitudes about abstainers. They recommended improving child self-control skills and increasing communication between parents and children about risky behaviors as useful strategies for prevention.

A recent review of preventive interventions targeting youth sexual behavior found that most interventions involving parents were effective in increasing communication, but the effects were not lasting and had little influence on youth sexual behaviors (Kirby and Miller 2002). In addition, most studies had methodological limitations (e.g., weak designs, small samples), did not build on relevant developmental theory or empirical findings, engaged adolescents late in the sexual development process (i.e., middle to late adolescence), and intervention content addressed enhancing parent-child sexual communication, but little else. Further, most were short in duration and focused on increasing parenting knowledge rather than building parenting skills. Similar critiques have been made of youth violence interventions (Thornton et al. 2002).

In addition to developing parenting skills, preventive interventions involving African American families must incorporate cultural content and meaningful activities that reflect the lived experiences and history of African Americans (Kumpfer et al. 2002; Potts 2003). Cultural factors such as shared beliefs in and value of the extended family and the interconnectedness of people among African Americans, for example, suggest the importance of engaging family members when working with African American youth (Harrison et al. 1990). Further, stress from jobs, un- or underemployment, and experiences with racial discrimination impinge upon the quality of family relationships and functioning, which have implications for youth risky behaviors (Bowman and Sanders 1998; Seaton et al. 2008; Williams et al. 2003). Cultural family processes such as race-related socialization (i.e., a parenting strategy for teaching children how to avoid or reduce race-related stress; Hughes and Chen 1997) and individual cultural factors such as racial identity can be protective against environmental stressors and youth risky behaviors (Caldwell et al. 2004a, b; Wills et al. 2007). Helping parents with race-related socialization tasks is an important area for parenting skills interventions with African American families.

Several recent interventions have effectively engaged African American parents and adolescents, while addressing a number of the above concerns. Guided by specific 
aspects of social cognitive theory (i.e., self-efficacy and outcome expectations), DiIorio et al. (2006) HIV preventive intervention focused on mostly African American residential fathers of 11-14 year old boys. It emphasized parent-child communication about sex. The fathers and sons participated in the last intervention session together. This 7-session intervention was successful in enhancing the fathers' ability to communicate with their sons about sexual matters. In addition, self-efficacy for sexual communication mediated intervention effects. That is, fathers' self-efficacy or confidence to talk with their sons about sexual matters was enhanced by the intervention, and fathers' self-efficacy for sexual communication was then directly associated with fathers' reports of increased communication about sex with their sons. Sex communication outcomes for the sons in this study were not significant. Nevertheless, intervention studies such as DiIorio et al. (2006) provide a foundation from which to begin to understand potential effective intervention strategies with African American fathers. They suggest that promoting self-efficacy in sexual communication interventions with fathers may be warranted.

\section{The Current Study}

The current study examined the effectiveness of the Fathers and Sons Program for enhancing the parenting skills of nonresident African American fathers in an effort to prevent future risky health behaviors of their preadolescent sons. This study also examined the effects of the intervention on father-son interactions, intentions to avoid violence, and aggressive behaviors among sons. We used a community-based participatory research approach (CBPR, Israel et al. 2005) to develop the intervention program to make it culturally specific and relevant to nonresident African American fathers and sons. The conceptual model that guided intervention development and implementation incorporated multiple theories, empirical findings, community perspectives, and the experiences of the nonresident families involved in focus groups and pilot testing the intervention (Caldwell et al. 2004a, b). Below we describe the conceptual model for the study.

The Fathers and Sons Program was based on a conceptual model that incorporated the theory of reasoned action (TRA, Ajzen and Fishbein 1980), four components of social cognitive theory (Bandura 1977), models of social networks and social support (Israel and Rounds 1987), race-related socialization (Thornton et al. 1990), and racial identity as a concept of the self-system among African Americans (Sellers et al. 1998). The TRA was at the core of the conceptual model because of the intentionality and future orientation in its conceptualization. Specifically, TRA suggests that the most important determinants of behaviors are behavioral intentions. An individual's behavioral intentions depend on his or her attitudes and subjective norms. Attitudes are the beliefs about specific behaviors and the outcomes if the behaviors are performed. Subjective norms are normative beliefs that depend on what people who are important to the individual think about the behaviors and the individual's motivation to comply with what these important people think. TRA assumes that an individual will process information and be motivated to act based on that information (Montano et al. 1997).

Our model suggested that the Fathers and Sons intervention would directly influence attitudes about the outcomes of interest (e.g., parent-child communication, sons' intentions to avoid violence) and subjective norms. To influence subjective norms, for example, fathers must communicate their moral values and expectations about youth risky behaviors to their sons and sons must understand and want to do what their fathers want them to do. Both attitudes and subjective norms were expected to directly influence how fathers and sons planned to act in the future (i.e., behavioral intentions). Parenting attitudes and behaviors such as monitoring and race-related socialization practices for fathers, and attitudes and behaviors regarding father-son interactions and aggressive behaviors for sons were included as proximal outcomes in the model, while substance use, serious violent behavior, and sexual debut were considered distal outcomes for the preadolescent boys in this study.

We also relied on components of Bandura's (1977) social cognitive theory (i.e., the social environment, behavioral capacity, and observational learning), and models of social networks and social support as described by Israel and Round (1987), and Thornton et al.'s (1990) race-related socialization to broaden the individual focus of TRA to incorporate interpersonal interactions between fathers and sons, and the larger community. For example, our model suggested that fathers' ability to monitor their sons would be captured as part of the social environment because negotiations with the mother of the child are critical aspects of their reality. In addition, through observational learning, fathers serve as role models for their sons. Behavioral capacity for effective communication between fathers and sons requires skill-building for both. These components were considered mediators between background characteristics and behavioral intentions. Factors that could facilitate the translation of behavioral intentions into action were conceptualized as moderators. These included social support and cultural resources. Community resources to assist fathers with their parenting responsibilities (e.g., employment offices, health and social service agencies) are examples of social support, which are functional aspects of social networks. Race-related 
socialization, a vital cultural protective strategy within African American families (Hughes and Chen 1997; Thornton et al. 1990), is the conveying and receiving messages about what it means to be Black in this society. It was included as a modifying factor in our model. Finally, racial identity was incorporated in the model as a moderator because in a number of studies of risky behaviors with African American adolescents it has been found to be a significant moderator (Sellers et al. 2006). The Fathers and Sons Program was expected to directly enhance all of the mediating and moderating components of the conceptual model.

The current study examined the effectiveness of the Fathers and Sons Program for enhancing specific parenting attitudes and behaviors for fathers, and attitudes and behaviors regarding father-son interactions and risky behaviors for sons. It was not designed to test the full conceptual model. The specific study hypotheses were: (a) fathers participating in the Fathers and Sons intervention will show greater improvements in their parenting attitudes and behaviors (i.e., monitoring, parent-child communication in multiple areas, race-related socialization, and parenting skills satisfaction) than fathers in the comparison group; (b) sons in the intervention will report more improvement in their interactions with their fathers (i.e., monitoring, parent-child communications in multiple areas, race-related socialization), increase their intentions to avoid violence, and show less aggressive behaviors than sons in the comparison group.

\section{Method}

\section{Study Design and Participants}

This study uses a quasi-experimental, non-equivalent group, pretest-posttest design to evaluate intervention effectiveness. Sample selection criteria were: (a) African American biological fathers and their 8-12 year old sons who were not living together, (b) mothers or legal guardians of the sons consented for the nonresident fathers to be involved with their sons, and (c) fathers could not be functionally impaired by substance abuse problems. Three fathers were not biological fathers. They were allowed to participate because they functioned in the father role prior to or soon after the child's birth and the biological father was never part of the child's life due to death, jail or another reason.

Families were recruited from two Midwestern cities with similar demographic characteristics. Local communitybased organizations assisted with recruitment, including family service organizations, public libraries, community centers, and schools in both cities. Data collection was conducted from the fall of 2002 until the fall of 2006 . Overall, 374 families were identified for the study and most enrolled to participate. A total of 188 families were eligible for the intervention group (i.e., met study criteria) and 162 completed the intervention. The number of intervention families included in data analyses was later reduced to 158 after four families were eliminated. These families were eliminated because the child was ineligible due to age $(n=2)$, a change occurred in living arrangements $(n=1)$, and a questionnaire was not usable from a family member $(n=1)$. Eliminating the three ineligible families due to age and living arrangements reduced the total number of eligible families to 185 . Thus, the response rate for the intervention group was $85.4 \%$.

A total of 186 eligible families were identified for the comparison group using the same procedures used for identifying families for the interventions study. We expanded the study to include a neighboring city because most families wanted to participate in the intervention rather than the comparison group, which only received the pretest and posttest questionnaires. We received IRB approval to collect comparison group data in a neighboring city with similar demographic characteristics as the intervention city. Pretest data were collected for 165 families. Posttest data, however, were available from only 129 comparison group families for a response rate of $69.4 \%$. The lower response rate for the comparison group was probably due to less frequent contact with families during the pretest-posttest interim resulting in a greater number of missed posttest assessments. Multiple sons from the same families participated in either the intervention $(17 \%)$ or comparison group (15\%) because they met study criteria. We did not want to potentially disrupt family harmony by asking fathers to select one eligible son over another eligible son; therefore, we allowed more than one son per family to participate in both the intervention and comparison groups. The results reported in this study are based on data from fathers and their eldest son if more that one son participated. The final study sample is 287 nonresident African American father-son families in both the intervention and comparison groups for an overall response rate of $77.4 \%$.

\section{Sample Description and Attrition Analysis}

The nonresident fathers in this study ranged in age from 22 to 63 , with a mean age of 37.4 (SD = 7.7). Few fathers were married $(13.2 \%)$, while $16.7 \%$ of the fathers were living with a partner, $16.4 \%$ were divorced, $9.4 \%$ were separated, $1.0 \%$ was widowed, and $43.2 \%$ were never married. Only $19.2 \%$ of the fathers were ever married to the mother of their sons in the study. The gender of the fathers' partners was not obtained. The majority of fathers 
had a high school/GED education or more $(78.1 \%)$ and about half $(51 \%)$ were employed. In terms of financial resources, most fathers $(55.7 \%)$ reported that they barely had enough or did not have enough money to get by. However, $73.2 \%$ also reported that they had a legal child support agreement for their sons. About $23 \%$ of the fathers never lived with their sons, while $77 \%$ lived with them at some time during their lifetime. Among fathers who had lived with their sons, most reported living with them until they were 5 years old or younger $(63 \%)$.

The sons in the study were $8-12$ years old, with an average age of $10.2(\mathrm{SD}=1.4)$. Their average grade at the time of the study was about 5 th grade $(\mathrm{SD}=1.4)$, and on average, they had 3.5 siblings $(\mathrm{SD}=2.5)$. From the sons' perspective, $63.1 \%$ remembered living with their father at some time during their lifetime.

Table 1 provides the results of chi-square analyses and $t$-test comparing intervention and comparison group families on demographic characteristics. Fathers and sons in both groups were similar on background characteristics with a few exceptions. Comparison group fathers had more education than intervention group fathers, $\chi^{2}(5, N=$ $287)=5.86, p<.05$. They also were more likely to have lived with their sons for a longer time, $\chi^{2}(5, N=$ $287)=10.28, p<.01$. Differences among sons were that comparison group sons were older, $t(285)=2.58$, $p=<.05$, and intervention sons had more siblings, $t(285)=3.91, p<.00$, than their counterparts. These variables were included as covariates in all multivariate analyses to control for sociodemographic differences between groups. Because of the wide age range among fathers, we included age as a covariate for fathers as well.

An attrition analysis was conducted to determine if characteristics of fathers and sons who completed posttest interviews ( $n=287$ families) were similar when compared to the $17 \%$ of families who did not complete the posttest ( $n=60$ families). A logistic regression analysis was conducted to regress the log odds of attrition (i.e., incomplete family data) on several baseline demographic factors (i.e., age, education, marital status, employment, child support agreement, and length of time lived together for fathers; and age, number of siblings, and ever lived with father for sons). The pretest measures of outcomes were included in these analyses. We found that fathers with a high school education were less likely to complete the posttest than those with more than a high school education, $\mathrm{OR}=.40$, $\mathrm{CI}=(.17, .95), p<.05$. Fathers who lived with their sons longer before becoming nonresident also were more likely to complete the posttest than those with less time together, $\mathrm{OR}=1.39, \mathrm{CI}=(1.01,1.82), p<.05$. Sons who lived with their fathers at some point were more likely to complete the posttest than those who had not, $\mathrm{OR}=2.03$, $\mathrm{CI}=(1.01,4.06), p<.05$, and sons who reported better general communication with their fathers were less likely to complete the posttest than those with worse communication, $\mathrm{OR}=.89, \mathrm{CI}=(.78,1.00), p<.05$.

\section{Procedures}

Following a community-based participatory research (CBPR) approach (Israel et al. 2005), representatives from several local community-based organizations, the local health department, and the Prevention Research Center of Michigan joined with community residents to form the project's steering committee. This committee represented an equal partnership responsible for developing the intervention and overseeing all aspects of the project. Community leadership in the research process gave the project legitimacy in the community and encouraged families to participate who otherwise may have been reluctant to do so.

Implementing the TRA required obtaining information about the target audience under different conditions in an effort to learn about a variety of issues and potential solutions. This process is called elicitation interviews (Ajzen and Fishbein 1980). We conducted elicitation focus groups with fathers and sons who met study criteria for residential status (i.e., nonresident) and those who did not (i.e., residential). We also conducted focus groups with mothers of nonresident African American sons. Eight elicitation focus groups (two nonresident fathers, two nonresident sons, two mothers of nonresident sons, and two resident families) were conducted to obtain information about the experiences of both nonresident and resident father-son families ( $N=77$ participants). This information, especially information from the two focus groups with non-resident fathers ( $n=17$ participants) and two focus groups with nonresident sons $(n=20$ participants), provided content and context for curriculum development for the intervention.

An additional 25 nonresident African American fatherson families participated in five pilot tests of the intervention curriculum and study questionnaires. The five pilot tests involved an average of five father-son families per group who met study criteria. These families participated in early versions of the intervention, providing critical feedback on different aspects of the curriculum as it was being developed and refined. The families tested multiple intervention modules, including revised versions of the content for each module, and the design and presentation of materials. It was during the pilot testing phase of the study that participants told us of their preference for a condensed timeframe for the intervention with multiple sessions per week. Consequently, we instituted a twice per week implementation strategy conducted over about 2 months instead of the original 4 months. This change contributed to a reduction in the attrition rate for the study. 
Table 1 Background characteristics at pretest by intervention and comparison groups

\begin{tabular}{|c|c|c|c|}
\hline Background characteristics & $\begin{array}{l}\text { Intervention } \\
(n=158)\end{array}$ & $\begin{array}{l}\text { Comparison } \\
(n=129)\end{array}$ & $X^{2}$ or $t$-test \\
\hline \multicolumn{4}{|l|}{ Fathers' characteristics } \\
\hline Age in years $(M, \mathrm{SD})$ & $37.4(7.2)$ & $37.5(8.3)$ & NS \\
\hline \multicolumn{4}{|l|}{ Marital status (\%) } \\
\hline Married/partner & 25.3 & 35.7 & \multirow[t]{3}{*}{ NS } \\
\hline Widowed/divorced/separated & 28.5 & 24.8 & \\
\hline Never married & 46.2 & 39.5 & \\
\hline \multicolumn{4}{|l|}{ Ever married to sons' mother (\%) } \\
\hline Yes & 17.7 & 20.9 & \multirow[t]{2}{*}{ NS } \\
\hline No & 82.3 & 79.1 & \\
\hline \multicolumn{4}{|l|}{ Education (\%) } \\
\hline Less than high school diploma & 22.2 & 20.9 & \multirow[t]{3}{*}{$*$} \\
\hline High school diploma/G.E.D. & 36.7 & 24.8 & \\
\hline More than high school & 41.1 & 54.3 & \\
\hline \multicolumn{4}{|l|}{ Employment status (\%) } \\
\hline Working & 51.9 & 49.6 & \multirow[t]{3}{*}{ NS } \\
\hline Not working & 36.7 & 38.0 & \\
\hline Temporarily laid off & 11.4 & 12.4 & \\
\hline \multicolumn{4}{|l|}{ Perceptions of financial resources $(\%)$} \\
\hline Not enough to get by & 26.6 & 26.4 & \multirow[t]{4}{*}{ NS } \\
\hline Barely enough to get by & 25.9 & 33.3 & \\
\hline Enough to get by & 36.7 & 35.7 & \\
\hline More than enough to get by & 10.8 & 4.7 & \\
\hline \multicolumn{4}{|l|}{ Legal agreement for child support (\%) } \\
\hline Yes & 70.9 & 76.0 & \multirow[t]{2}{*}{ NS } \\
\hline No & 29.1 & 24.0 & \\
\hline \multicolumn{4}{|l|}{ Ever lived with sons (\%) } \\
\hline Yes & 75.3 & 79.1 & \multirow[t]{2}{*}{ NS } \\
\hline No & 24.7 & 20.9 & \\
\hline \multicolumn{4}{|l|}{ How long lived with sons (\%) } \\
\hline Never lived with sons & 24.7 & 20.9 & \multirow[t]{3}{*}{$*$} \\
\hline Lived with son 5 years or less & 55.1 & 41.9 & \\
\hline Lived with son more than 5 years & 20.3 & 37.2 & \\
\hline \multicolumn{4}{|l|}{ Sons' characteristics } \\
\hline Age in years $(M, S D)$ & $9.98(1.4)$ & $10.40(1.4)$ & $*$ \\
\hline Current grade level $(M, S D)$ & $4.69(1.4)$ & $4.98(1.4)$ & NS \\
\hline Number of siblings $(M, S D)$ & $3.95(2.7)$ & $2.84(2.1)$ & $*$ \\
\hline \multicolumn{4}{|l|}{ Ever lived with father $(\%)$} \\
\hline Yes & 60.1 & 66.7 & \multirow[t]{2}{*}{ NS } \\
\hline No & 39.9 & 33.3 & \\
\hline
\end{tabular}

$* p<.05$

The final intervention curriculum consists of 15 sessions. The first and last sessions were 3 hours, while other sessions were 2 hours. The first session was an overview of the purpose of the Fathers and Sons Program consistent with recruitment materials, a review of required administrative forms, including consent and assent forms, a delineation of rules for participation, an assignment of roles for sons (e.g., rule keeper, time keeper, set-up assistant), and an opportunity for open discussion on topics designed to engage families but avoid influencing the pretest. Session 1 
Table 2 The fathers and sons program curriculum

Session 1: program overview

Overview, expectations; diversity among families; adolescent development

Session 2: setting the stage

Focus group discussion of issues; description of memory book

Session 3: people of African heritage

African symbolism and culture; ethnic pride; memory book activity

Session 4: health enhancement strategies I

Safety and physical activities; bonding through recreation; group naming activity

Session 5: general communication

Verbal and non-verbal communication skill-building

Session 6: fathers and sons having their say

What works, what does not work, strategies for success, group assessment

Session 7: family functioning and parenting behaviors

Family values \& responsibilities; family roles \& discipline strategies; parent-child relationships; parent involvement \& monitoring for non-resident parents

Session 8: parenting behaviors and social relationships

Parent-child expectations; social network characteristics; social support resources

Session 9: using computers to communicate and monitor

Introduction to the internet; communicating via email; parental monitoring

Session 10: communication about risky behaviors I

Substance use; communicating moral values \& expectations; practicing refusal skills

Session 11: communication about risky behaviors II

A. Violent behavior:

1. Communicating moral values $\&$ expectations

2. Practicing conflict management skills

B. Sexual behavior:

1. Communicating moral values \& expectations

2. Practicing refusal skills

Session 12: health enhancement strategies II

Physical activity \& active teaching moments; strengthening family relationships

Session 13: culture and health

A cultural experience: making the connection for health; making the connection for family

Session 14: information gathering II: posttest; focus group data collection

Session 15: closing ceremony: graduation

occurred 1 week prior to the other sessions. The goal was to create a safe and trusting environment so that participants would want to return and to be sure that all necessary paperwork was received. Table 2 provides the content of each session.

Pretest data were collected prior to substantive activities for Session 2. During pilot testing we found that the pretest questionnaire evoked a desire to discuss issues covered in the questionnaire; therefore, the content portion of the intervention began with focus groups during Session 2 so that fathers and sons could share their feelings, concerns, and experiences related to program goals. Posttest data were collected at the end of the intervention (Session 14). All participants were assessed at the end of the intervention regardless of the number of sessions they attended. This procedure was done so that no families were eliminated from the study because they did not attend all sessions. Unlike the content-driven and skill-building sessions, the final session (Session 15) was a closing ceremony where family members (e.g., mothers, siblings) were invited to participate as important members of the fathers' and sons' social support networks. Highlights included a graduation ceremony during which the fathers and sons received certificates of program completion and they had an opportunity to celebrate their success through poster displays and their Memory Books.

The Fathers and Sons intervention includes 32 contact hours. In addition to the introductory and closing sessions, there are 24 hours of specific activities designed to enhance knowledge, influence attitudes, and practice skill-building 
in specific content areas (e.g., culture and history, effective parent-child communication, parental monitoring, role modeling, social support and networking behaviors, cultural connections, preventing or reducing substance use, violent behavior, and early sexual debut). The curriculum also includes nine homework assignments and 4 hours of community cultural activities for a total of 45 hours over about a 2-month period. The homework assignments and community activities are meant to reinforce learning based on structured intervention sessions. Each session began and ended with a 10-min Check-In and Check-Out period so that families had time to discuss what was important to them. This approach was used to encourage participant ownership of and commitment to the intervention by incorporating relevant events in their lives on an ongoing basis.

\section{Intervention Implementation}

The Fathers and Sons Program was rooted in the historical experiences of Africans and African Americans as culture and history are infused throughout with a specific focus on cultural issues in some sessions and cultural symbolism in other sessions. This approach is exemplified in emancipatory education programs often found in violence prevention interventions for African American youth (Potts 2003). The significance of incorporating a cultural approach that considers historical and contemporary issues that have contributed to African American men being nonresident fathers and addressing issues of father responsibilities was reinforced during focus groups conducted with nonresident fathers and sons at every pilot test of the intervention, and by our community partners. The importance of having a cultural component may be reflected in the high level of engagement in the intervention program. The average attendance for the 15 intervention sessions was 12.22 ( $\mathrm{SD}=3.13$ ) for fathers and 12.50 ( $\mathrm{SD}=3.07$ ) for sons. Moreover, $77.2 \%$ of fathers and $79.6 \%$ of sons attended 11 or more of the 15 sessions.

Prior to beginning the intervention, an orientation meeting was held with families, including mothers, to meet the research project staff, including the principal investigator and other staff members who would not be present at the intervention. This was an opportunity to share information about the program, but also for mothers' voices to be heard. The intervention was implemented in groups of mostly 6-12 families, with an average of 8 families per group. Fathers were paid $\$ 30$ per session for their participation and sons were paid $\$ 15$ per session. Fathers provided written consent for their own participation, while mothers or legal guardians provided written consent for sons. The sons also provided written assent for themselves. As a CBPR project, this study was approved by the university's Health Sciences Institutional Review Board and an Institutional Review Board of a local Medical Center for our community partners.

\section{Missing Data}

Families with both a pretest and posttest for fathers and sons in the same family were included in the final sample for this study. Nevertheless, missing data occurred due to skipped questions or unavailable responses. Missing data were replaced using an expectation maximization (EM) algorithm to obtain maximum likelihood (ML) estimates (Ullman and Bentler 2003, p. 615). Fox-Wasylyshyn and El-Masri (2005) indicated that EM will produce less biased parameters when data are missing at random (MAR). Following a procedure suggested by these authors, we conducted a series of logistic regression analyses using a missingness dummy variable $(0=$ missing data and $1=$ complete data $)$ for study outcomes at posttest as the dependent variables and covariates and demographic variables as predictors. Findings suggested that the patterns of missing data were likely to be MAR. Assessments of the patterns of missingness matrices revealed that only two patterns had more than $2 \%$ missing cases in the analysis for fathers and in the analysis for sons. The results reported for this study are based on estimated data.

\section{Measures}

\section{Intervention Outcomes}

Parental Monitoring A commonly used index of parental monitoring (Jacobson and Crockett 2000) that assessed parents' knowledge about their children's whereabouts and activities was used to measure parental monitoring. It included five questions about fathers' knowledge of their sons' activities (e.g., after-school activities, week night activities, weekend routines, homework habits). A 4-point response scale was used that ranged from $1=$ nothing at all to $4=\mathrm{a}$ lot. Index scores ranged from 5 to 20 ; higher scores indicated more monitoring. Parallel measures for fathers and sons assessed the fathers' monitoring behavior. Cronbach's alpha at pretest for fathers was .82 and .77 for sons.

Parent-Child Communication Barnes and Olson's Parent-Child Communication Scale (as reported in Forehand et al. 1997) is a general parent-child communication scale designed to assess the quality of communication between parent and child. Eight items that specifically assessed the perceived ease of communication between fathers and sons comprised this scale. Examples of items are: for fathers"My son and I can talk about almost anything." For sons- 
"My father and I can talk about almost anything." A 4-point response scale ranging from $1=$ strongly disagree to $4=$ strongly agree was used. Scale scores ranged from 8 to 32 ; higher scores indicated better communication. Cronbach's alpha at pretest for fathers was .64 and .67 for sons.

Communication About Sex The Blake's Parent-Child Communication Scale (Blake et al. 2001) is a measure of the frequency of parent-child communication about several topics. The 4-item subscale about sexual matters was used to assess this construct. Examples of items included are: How often have you talked with your father/son about: "How to get along with girls," "Reasons to wait to have sex," and "How the body changes during puberty." Response categories were $1=$ never, $2=$ one or two times, $3=3-5$ times, $4=6$ or more times. Scale scores ranged from 4 to 16; higher scores indicated more frequent communication about sexual matters. Cronbach's alpha at pretest for fathers was .89 and .83 for sons.

Risky Behavior Communication The Youth Assets Scale (HEART of OKC 2002) is a measure of parent-child communication about multiple risky behaviors, including the extent of topics covered and the efficacy or confidence for improving one's ability to discuss risky behaviors. We used this measure to assess whether or not fathers and sons talked about what was right or wrong about six different risky behaviors (i.e., alcohol use, smoking cigarettes, violent behavior, having sex, marijuana use, and other drugs). A Yes/No response category was used. We created two measures of risky behavior communication based on the Youth Assets Scale: (a) a count of the range of different topics discussed, which is the extent of risky behavior communication, and (b) the efficacy or confidence in fathers' or sons' ability to improve their communication about different risky behaviors. This measure represented a count of the range of risky behaviors for which fathers or sons were confident that they could improve their own ability to talk with each other. Total counts ranged from 0 to 6 for both measures. Most fathers answered the efficacy items in the affirmative at pretest; therefore, this measure was not included as an outcome for fathers. It is included as an outcome for sons. Higher numbers on both measures represented better risky behavior communication.

Behavioral Intentions Ajzen and Fishbein's (1980) procedure for crafting the concept of behavioral intentions in TRA was used to develop the measure of fathers' intentions to communicate with their sons in the future. Behavioral intentions measures based on TRA are typically developed for a specific behavior. All components of TRA were operationalized for the current study. Example questions are: "Better communication with my son will make us closer," which represented an attitude belief about an outcome if a specific behavior was performed for fathers. "My son thinks it's important for us to improve our communication" is an example of what an important person thinks about the behavior for fathers. This question represented the normative beliefs component of subjective norms, while "I want to do what my son thinks is right concerning our communication" is a question about fathers' motivation to comply with their sons' opinions about the behavior. The original measure by Ajzen and Fishbein (1980) used a 7-point response scale ranging from -3 to +3 . We reduced the response categories to a 4-point scale $(1=$ strongly disagree to $4=$ strongly agree $)$ for clarity with our population based on pilot tests of the measure. The final scale was developed by multiplying components of attitudes and subjective norms and adding them to create the intentions to communicate with sons in the future measure for fathers. The 4-item measure was then divided by four to provide an overall mean score for the scale. Total scores ranged from 1 to 4 ; higher scores indicated more intentions to communicate with their sons in the future.

The Intentions to Use Non-Violent Strategies Scale (Bosworth et al. 1999) is a scale that was developed to assess children's plans to use alternative violent strategies in future anger-provoking situations. This 8-item scale included questions such as: "Please tell me how often you would do any of the following things the next time you get really angry: try to talk it out with the person, try not to be so angry, ask for advice from your father." Response categories were on a 4 -point scale, with $1=$ never to $4=$ all the time. Scale scores ranged from 8 to 32; higher scores indicated more intentions to use non-violent strategies or avoid violence. Cronbach's alpha at pretest for sons was .73.

Race-Related Socialization The Racial Socialization Scale (Martin 2000) is a measure of what fathers taught sons about what it means to be Black. This measure was adapted from the National Survey of Black Americans (Thornton et al. 1990). Language modifications were necessary for administering this measure to 8-12 year olds because the NSAL sample only included youth as young as 13. Modifications were tested during the pilot phase of the study. Ten items assessed race-related socialization practices for fathers and what sons remembered fathers saying or doing in this area. Examples of questions included how often: "I teach (or model to) my child that all individuals are equal in this society" for fathers and "...father tells you to be proud of Black history for sons." A 4-point response scale was used, with $1=$ never and $4=$ all the time. Scale 
scores ranged from 10 to 40; higher scores indicated more race-related socialization. Cronbach's alpha at pretest for fathers was .73 and it was .76 for sons.

Parenting Skills Satisfaction Two single-item parenting skills satisfaction questions were asked to assess: (a) how satisfied fathers were with their ability to supervise their sons, and (b) how satisfied fathers were with their overall parenting skills. Both questions were assessed on a 4-point response scale, with $1=$ very dissatisfied to $4=$ very satisfied. Because of the high correlation between the two questions $(r=.64, p<.000)$, we created an index for parenting skills satisfaction to represent a dimension of fathers' attitudes about parenting based on these two questions. Summed scores ranged from 2 to 8 ; higher scores indicated more satisfaction with their parenting skills for fathers. Cronbach's alpha for this measure at pretest for fathers was .78 .

Role-Modeling Behavior The CAGE (Winters and Zenilman 1994) brief alcohol assessment tool was used to determine problematic drinking behavior among fathers. The CAGE is a 4-item instrument commonly used in brief alcohol interventions. Based on SCT, role modeling behavior is vital to observational learning. Thus, determining if fathers recognized and tried to alleviate their own problematic drinking behavior was a critical part of the intervention in an effort to prevent youth substance use behavior. To represent this construct, we focused on whether or not fathers who needed assistance with their drinking asked for help. Three questions were asked to assess whether or not fathers' drinking had caused concern, after determining the frequency of their drinking. A sample question is "Have you ever felt bad about some of the things you have done when you drink?" A follow-up question at posttest asked about whether or not fathers wanted professional assistance for alcohol abuse.

Aggressive/Violent Behavior Two questions developed by the research team based on frequently used questions from the literature were used to measure aggressive behavior. Each question had a 6-point frequency response scale ranging from $0=$ never to 5 or more times. These questions assessed if sons had been in a physical fight or hit or kicked people when angry in the previous 2 months. The questions were examined individually because of our interest in assessing the intervention's effect on different types of aggressive behavior among sons.

\section{Demographic and Control Variables}

Age, marital status, education, employment and number of siblings were measured with standard demographic questions. Perceptions of financial status were assessed with a single question that asked fathers: "How would you describe your financial situation today?" Response categories were: $1=$ not enough to get by, $2=$ barely enough to get by, $3=$ enough to get by, but no extras, and $4=$ more than enough to get by. Both fathers and sons were asked if they had ever lived together, but only fathers who had ever lived with their son were asked how long they had lived together. Specifically, fathers were asked: "Have you ever lived in the same house with your son who is here with you today?" If, yes: "How long did you live with your son who is here with you today?" The following response categories were used to provide an age context as the focus of the response: Until he was: (a) $<1$ year old, (b) 1-5 years old, (c) 6-7 years old, (d) 8-10 years old, and (e) 11-12 years old. These categories were selected to represent developmental milestones and to reflect critical age demarcations for the study (i.e., 8-10, 11-12). Pilot testing with nonresident African American fathers was useful for confirming these age categories as meaningful periods they could recall.

\section{Data Analytic Strategy}

Separate sets of Analysis of Covariance (ANCOVAs) were conducted for fathers and for sons to test the effects of the intervention on outcomes of interest. Seven outcome measures were assessed for fathers, with pretest scores for each outcome, age, education, and time lived with sons included in the analyses as covariates. The analyses included nine outcomes for sons, with pretest scores for each outcome, age and number of siblings included as covariates. Covariates were included in these analyses to partial out the effects of preintervention group differences because we did not randomize groups. ANCOVA tables include the estimated marginal means for all analyses. An alpha of .05 was established as the criterion for significant results.

Analyses were conducted using SPSS 14.0, which produces an index of effect sizes within the context of general linear models using the partial $\eta^{2}$. Partial $\eta^{2}$ may be used like Cohen's $d$ (Cohen 1988) to assess the effect of the intervention; however, the metric for determining effect size is different. Based on the partial $\eta^{2}$, small, medium, and large effects are $.01, .06$, and .14, respectively (Stevens, 1996 as cited in D'Amico et al. 2001).

Prior to running the ANCOVAs, $t$-tests were conducted to compare intervention and comparison group participants for equivalency on all outcomes at pretest. Fathers were similar on all pretest assessments of outcomes except the extent of risky behavior communication. Comparison group fathers, $M=5.30, \mathrm{SD}=1.44$, reported communicating about a wider range of risky behaviors with their 
sons than intervention group fathers, $M=4.80$, $\mathrm{SD}=1.92, t(285)=2.44, \quad p<.05$. Comparison group sons indicated higher efficacy to improve risky behavior communication with their fathers, $M=5.20, \mathrm{SE}=1.78$ vs. $M=4.66, \mathrm{SE}=2.25 ; t(285)=2.42, p<.05$, and intentions to avoid violence than intervention group sons, $M=20.88, \mathrm{SE}=4.40$ vs. $M=19.34, \mathrm{SE}=4.78 ; t(285)=$ $2.80, p<.05$. Intervention sons reported more race-related socialization than comparison group sons, $M=22.69$, $\mathrm{SE}=6.07$ vs. $M=21.25, \mathrm{SE}=5.89, t(285)=2.04, p<.05$.

\section{Results}

Table 3 presents the means and standard deviations for all outcome measures at pretest and posttest for the intervention and comparison groups for both fathers and sons. The intercorrelations between pretest outcomes for fathers and sons are presented in Table 4. Among fathers, parental monitoring was modestly correlated with all other parenting variables with the exception of the extent of risky behavior communication. Race-related socialization and parenting skills satisfaction also were correlated with most other father outcomes. Although there were several significant correlations, none of them were higher than $r=.38$, suggesting that the outcomes represent independent constructs. Significant correlations between father and son outcome measures were generally low (see Table 4). All outcomes were positively correlated for sons with the exception of general parent-child communication and confidence about communicating about risky behaviors. Correlations for the sons' outcomes were stronger than those for the fathers' outcomes and for the correlations between father and son outcomes.

The results of the ANCOVA analyses for fathers, along with effect sizes, are presented in Table 5, while results for sons are presented in Table 6. Findings for fathers indicated that there was a significant effect of the intervention for five out of the seven outcomes. Specifically, the intervention had a significant main effect on fathers' parental monitoring behavior, communication about sex with their sons, intentions to communicate with their sons in the future, race-related socialization practices, and parenting skills satisfaction. Intervention main effects for sons were significant for five out of the nine outcomes. Findings indicated that monitoring by fathers, communication about sex with fathers, and intentions to avoid violence improved for sons in the intervention. There were also significant main effects of the intervention for physical fighting and hitting or kicking when angry among sons. These results, however, indicated that these aggressive behaviors decreased among sons in the comparison group significantly more than among sons in the intervention group. The effect sizes for all main effect findings were small, ranging from partial $\eta^{2}=.02-.05$.

Table 3 Means and standard deviations at pretest by intervention and comparison groups

\begin{tabular}{|c|c|c|c|c|}
\hline & \multicolumn{2}{|c|}{ Intervention group $(n=158)$} & \multicolumn{2}{|c|}{ Comparison group $(n=129)$} \\
\hline & Pretest means (SD) & Posttest means (SD) & Pretest means (SD) & Posttest means (SD) \\
\hline \multicolumn{5}{|l|}{ Fathers' outcomes } \\
\hline Parental monitoring & $15.68(3.47)$ & $16.18(3.19)$ & $16.37(3.07)$ & $16.16(3.11)$ \\
\hline Parent-child communications & $24.24(3.58)$ & $24.98(3.78)$ & 24.35 (3.59) & $25.02(4.07)$ \\
\hline Communication about sex & $9.77(4.33)$ & $11.00(4.25)$ & $10.17(4.15)$ & $11.09(4.06)$ \\
\hline Risky behavior comm. extent & $4.80(1.92)$ & $5.54(1.15)$ & $5.30(1.44)$ & $5.51(1.10)$ \\
\hline Intentions to communicate & $3.31(0.60)$ & $3.44(0.45)$ & $3.30(0.55)$ & $3.27(0.59)$ \\
\hline Race-related socialization & $24.94(4.62)$ & $26.53(4.18)$ & $25.56(4.61)$ & $25.44(4.94)$ \\
\hline Parenting skills satisfaction & $6.37(1.39)$ & $6.91(1.00)$ & $6.28(1.60)$ & $6.43(1.55)$ \\
\hline \multicolumn{5}{|l|}{ Sons' outcomes } \\
\hline Parental monitoring & $14.69(3.86)$ & $15.41(3.78)$ & $15.05(3.72)$ & $15.32(3.21)$ \\
\hline Parent-child communications & $24.54(3.65)$ & $25.09(3.18)$ & $25.11(4.09)$ & $24.77(2.74)$ \\
\hline Communication about sex & $9.15(4.00)$ & $10.11(4.18)$ & $8.43(3.78)$ & $8.65(3.84)$ \\
\hline Risky behavior com. efficacy & $4.66(2.25)$ & $5.23(1.76)$ & $5.20(1.78)$ & $5.46(1.53)$ \\
\hline Risky behavior comm. extent & $4.70(1.98)$ & $4.66(2.14)$ & $4.56(2.06)$ & $4.47(1.95)$ \\
\hline Race-related socialization & $22.69(6.07)$ & $24.26(6.04)$ & $21.25(5.87)$ & $22.04(5.61)$ \\
\hline Intentions to avoid violence & $19.34(4.78)$ & $20.57(4.90)$ & $20.88(4.40)$ & $20.89(4.01)$ \\
\hline Physical fighting & $1.30(1.65)$ & $1.52(1.68)$ & $1.22(1.61)$ & $0.80(1.25)$ \\
\hline Hit or kick when angry & $1.50(1.52)$ & $1.11(1.73)$ & $0.81(1.29)$ & $0.51(1.06)$ \\
\hline
\end{tabular}




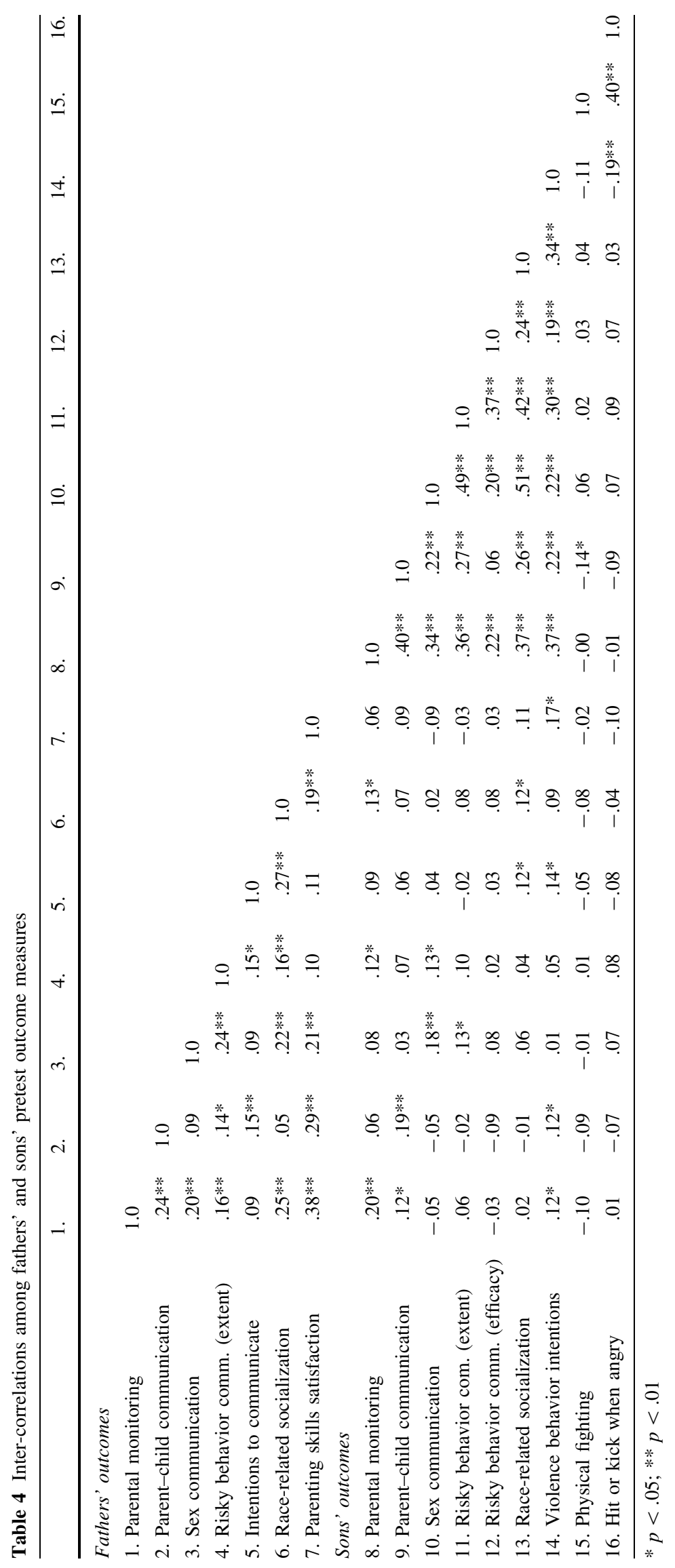


Table 5 ANCOVA results for fathers' parenting outcomes

\begin{tabular}{|c|c|c|c|c|c|}
\hline \multirow[t]{2}{*}{ Outcomes } & \multirow{2}{*}{$\begin{array}{l}\text { Intervention }(n=158) \\
\text { Mean (SE) }\end{array}$} & \multirow{2}{*}{$\begin{array}{l}\text { Comparison }(n=129) \\
\text { Mean }(\mathrm{SE})\end{array}$} & \multicolumn{3}{|c|}{ Group partial } \\
\hline & & & $F^{\mathrm{a}}$ & $p$-value & $\eta^{2}$ \\
\hline \multicolumn{6}{|c|}{ Parental monitoring } \\
\hline Pretest & $15.73(0.26)$ & $16.32(0.29)$ & - & - & \\
\hline Posttest & $16.37(0.20)$ & $16.00(0.23)$ & 4.30 & 0.04 & 0.02 \\
\hline \multicolumn{6}{|c|}{ Parent-child communication } \\
\hline Pretest & $24.25(0.28)$ & $24.34(0.32)$ & - & - & \\
\hline Posttest & $24.98(0.27)$ & $25.02(0.30)$ & 0.01 & NS & 0.00 \\
\hline \multicolumn{6}{|c|}{ Communication about sex } \\
\hline Pretest & $9.80(0.34)$ & $10.13(0.38)$ & - & - & \\
\hline Posttest & $11.09(0.30)$ & $11.04(0.33)$ & 6.13 & 0.01 & 0.02 \\
\hline \multicolumn{6}{|c|}{ Risky behav. comm. (extent) } \\
\hline Pretest & $4.83(0.14)$ & $5.27(0.15)$ & - & - & \\
\hline Posttest & $5.57(0.09)$ & $5.47(0.10)$ & 0.50 & NS & 0.00 \\
\hline \multicolumn{6}{|c|}{ Intentions to communicate } \\
\hline Pretest & $3.31(0.05)$ & $3.30(0.05)$ & - & - & \\
\hline Posttest & $3.44(0.04)$ & $3.27(0.04)$ & 8.75 & 0.00 & 0.03 \\
\hline \multicolumn{6}{|c|}{ Race-related socialization } \\
\hline Pretest & $24.91(0.37)$ & $25.60(0.41)$ & - & - & \\
\hline Posttest & $26.64(0.33)$ & $25.29(0.37)$ & 7.35 & 0.00 & 0.03 \\
\hline \multicolumn{6}{|c|}{ Parenting skills satisfaction } \\
\hline Pretest & $6.37(0.12)$ & $6.28(0.13)$ & - & - & \\
\hline Posttest & $6.87(0.08)$ & $6.48(0.09)$ & 11.79 & 0.00 & 0.04 \\
\hline
\end{tabular}

Estimated marginal means are reported; covariates are pretest outcome measures, fathers' age, education, and length of time lived with son

${ }^{a}$ ANCOVA assumptions were tested prior to conducting analyses. When a pretest outcome $\times$ group interaction term was significant and the slopes were both in the same direction in tests for homogeneity of regression slopes, we reported the $F$-value associated with the main effect of group

Fathers as Role Models

The concept of role modeling from SCT was assessed by examining the drinking behaviors of fathers. Alcohol was by far the most frequently used substance for this sample. We found no differences in the frequency of drinking beer, wine or alcohol among fathers in the intervention and comparison groups during the year prior to the pretest interview, $F(1,284)=.11, p=.74$. Overall, $23 \%$ of fathers indicated that they never drank, while $10 \%$ reported that they drank less than once a month. Twelve percent $(12 \%)$ reported that they drank exactly once a month, while $28 \%$ were weekly drinkers. More than a quarter $(27 \%)$ of the fathers drank several times per week or more. Those who drank averaged three drinks $(\mathrm{SD}=1.10)$ on one occasion. A total of $44 \%$ of the fathers felt a need to reduce their drinking at pretest, while $56 \%$ did not.

About $26 \%$ of intervention group fathers and $28 \%$ of comparison group fathers reported that they drank several times a week or more at posttest. Fifty-seven percent $(57 \%)$ of the fathers reported that they felt the need to reduce their drinking and $66 \%$ indicated that they intended to stop or reduce their drinking within 6 months of the posttest. Overall, $62.7 \%$ of intervention fathers who drank $(n=69)$ and $42.5 \%$ of comparison group fathers $(n=37)$ indicated that they intended to stop drinking within 6 months of the posttest, $\chi^{2}(1, N=287)=7.97, p<.01$. Thus, significantly more intervention group fathers were motivated to reduce or stop drinking at posttest than comparison group fathers. Fewer fathers in both groups thought that their drinking was a problem (14\% intervention, $n=19 ; 17 \%$ comparison, $n=16$ ).

Fathers who indicated problematic drinking were asked if they wanted assistance. Results showed that $66.7 \%$ of intervention fathers $(n=12)$ requested assistance as compared to $25 \%$ of comparison group fathers $(n=4)$. This difference was statistically significant, $\chi^{2}(1, N=34)=$ $5.90, p=.03$.

\section{Discussion}

The results of this study suggest that the Fathers and Sons Program is promising in enhancing several parenting 
Table 6 ANCOVA results for sons' outcomes for father-son interactions, intentions to avoid violence, and aggressive behaviors

\begin{tabular}{|c|c|c|c|c|c|}
\hline \multirow[t]{2}{*}{ Outcomes } & \multirow{2}{*}{$\begin{array}{l}\text { Intervention }(n=158) \\
\text { Mean (SE) }\end{array}$} & \multirow{2}{*}{$\begin{array}{l}\text { Comparison }(n=129) \\
\text { Mean }(\mathrm{SE})\end{array}$} & \multicolumn{3}{|c|}{ Group partial } \\
\hline & & & $F^{\mathrm{a}}$ & $p$-value & $\eta^{2}$ \\
\hline \multicolumn{6}{|c|}{ Parental monitoring } \\
\hline Pretest & $14.75(0.31)$ & $14.98(0.34)$ & - & - & \\
\hline Posttest & $15.46(0.24)$ & $15.32(0.26)$ & 13.41 & 0.00 & 0.05 \\
\hline \multicolumn{6}{|c|}{ Parent-child communication } \\
\hline Pretest & $24.67(0.31)$ & $24.95(0.34)$ & - & - & \\
\hline Posttest & $24.99(0.21)$ & $24.89(0.24)$ & 0.09 & NS & 0.00 \\
\hline \multicolumn{6}{|c|}{ Communication about sex } \\
\hline Pretest & $9.28(0.31)$ & $8.27(0.34)$ & - & - & \\
\hline Posttest & $9.90(0.29)$ & $8.91(0.33)$ & 4.97 & 0.03 & 0.02 \\
\hline \multicolumn{6}{|c|}{ Risky behav. comm. (efficacy) } \\
\hline Pretest & $4.63(0.17)$ & $5.23(0.18)$ & - & - & \\
\hline Posttest & $5.30(0.12)$ & $5.38(0.14)$ & 0.19 & NS & 0.00 \\
\hline \multicolumn{6}{|c|}{ Risky behav. comm. (extent) } \\
\hline Pretest & $4.75(0.16)$ & $4.51(0.18)$ & - & - & 0.00 \\
\hline Posttest & $4.64(0.16)$ & $4.49(0.17)$ & 0.39 & NS & \\
\hline \multicolumn{6}{|c|}{ Race-related socialization } \\
\hline Pretest & $22.69(0.49)$ & $21.25(0.54)$ & - & & \\
\hline Posttest & $23.82(0.38)$ & $22.41(0.43)$ & 1.92 & NS & 0.00 \\
\hline \multicolumn{6}{|c|}{ Intentions to avoid violence } \\
\hline Pretest & $19.32(0.37)$ & $20.90(0.41)$ & - & & \\
\hline Posttest & $20.88(0.33)$ & $20.74(0.37)$ & 5.17 & 0.02 & 0.02 \\
\hline \multicolumn{6}{|c|}{ Physical fighting } \\
\hline Pretest & $1.23(0.13)$ & $1.30(0.15)$ & - & & \\
\hline Posttest & $1.47(0.11)$ & $0.86(0.13)$ & 12.69 & 0.00 & 0.04 \\
\hline \multicolumn{6}{|c|}{ Hit or kick when angry } \\
\hline Pretest & $1.03(0.11)$ & $0.83(0.13)$ & - & & \\
\hline Posttest & $1.08(0.11)$ & $0.55(0.12)$ & 9.42 & 0.00 & 0.03 \\
\hline
\end{tabular}

Estimated marginal means are reported. Covariates are pretest outcomes, age and \# of siblings

${ }^{a}$ ANCOVA assumptions were tested prior to conducting analyses. When a pretest outcome $\times$ group interaction term was significant and the slopes were both in the same direction in tests for homogeneity of regression slopes, we reported the $F$-value associated with the main effect of group

attitudes and behaviors of nonresident African American fathers. Findings also suggest that sons benefitted from participating in the intervention in specific areas. Although the effect sizes were modest (partial $\eta^{2}$ ranged from .02 to $.05)$, we believe the findings are important for understanding more about engaging nonresident African American fathers and sons in family interventions aimed at addressing youth risky behaviors. They direct attention to areas of success and areas for improvement in the current intervention and provide valuable guidance for future community-based, family interventions and research.

Fathers participating in the intervention improved their ability to monitor their sons' activities and sons in the intervention reported more monitoring by their fathers. Monitoring is a key protective parenting behavior associated with a number of positive youth outcomes (Griffin et al. 2000; Walker-Barnes and Mason 2001). Strengthening monitoring behaviors among nonresident African American fathers has the potential to expand the number of adults available to supervise and protect African American boys as they engage in everyday activities. The results of this study suggest that nonresident African American fathers are capable of being knowledgeable about their sons' activities and are willing to provide oversight, even when they do not live in the same household. Institutions working with nonresident families (e.g., schools, health care systems, child welfare systems) could work with legal guardians and nonresident fathers to determine how to systematically involve fathers in monitoring their children.

Consistent with the DiIorio et al.'s (2006) study, fathers in the Fathers and Sons Program improved their ability to communicate with their sons about sex. Unlike the DiIorio 
et al. (2006) study, the sons' in our program also reported improvements in communicating with their fathers about sexual matters. This difference may have occurred because the Dilorio study primarily focused on fathers. The boys in their study only participated in one intervention session. Their study also demonstrated long-term results, while the Fathers and Sons Program is showing promising shortterm results. Taken together, the findings from both studies suggest that there is a need to help resident and nonresident African American fathers engage in discussions about sexual matters with their sons. The current study found that nonresident African American fathers can be engaged in the sexual socialization of their preadolescent sons after participating in an intervention that provides a safe and enriching setting for father-son relationship building. We were not able to assess a direct link between enhanced communication about sex between fathers and sons and early sexual debut because the boys in our study were not sexually active. Dittus et al. (1997), however, did find that fathers' disapproval was associated with delayed sexual debut among African American youth. Nonresident African American fathers and sons talking about sexual matters is a first step in communicating such disapproval. Further research is needed to determine the role of father-son communication about sex in preventing early sexual debut among African American boys.

One of the many challenges facing nonresident African American families is continued father involvement. Intervention fathers in the current study increased their intentions to communicate with their sons. Previous studies, however, show that there is diversity in the level of nonresident father involvement over time from no contact to intermittent involvement to extensive involvement (Coley and Medeiros 2007; Zimmerman et al. 2000). It will be necessary for future studies to determine what it will take for nonresident fathers to stay connected with their sons. Coley and Medeiros (2007) found that African American nonresident fathers increased their involvement with their adolescent children when their non-violent delinquent behaviors increased. Helping nonresident fathers stay connected with their children prior to the onset of adolescent risky behaviors may be advantageous for the child, the father, and the family. The TRA posits that behavioral intentions should directly influence future behaviors. Longitudinal studies are needed to determine if intentions to communicate do indeed translate into long-term protective behaviors among nonresident fathers and their children.

The Fathers and Sons Program addressed racial discrimination in the lives of African American men from a family perspective. This may have contributed to why racerelated socialization and parenting skills satisfaction were both enhanced among fathers in the program. Fagan and
Stevenson's intervention (2002) improved parenting satisfaction among African American resident and nonresident fathers of Head Start children. It did not, however, influence race-related socialization. This could have been because the average age of the fathers' children in the Fagan and Stevenson (2002) study was 5.9 years old. These fathers may not have been actively involved in the racial socialization process for their young child. The boys in the Fathers and Sons Program were at an age when racial issues were emerging as central to their identity development (Hughes and Chen 1997). Focusing on a relevant culturally based parenting skill for African American fathers offered them an opportunity to provide their sons with life lessons for negotiating race-related issues. Engaging in meaningful activities, learning about different parenting approaches, sharing their experiences, and succeeding with new parenting strategies may have contributed to the improved parenting skills satisfaction for the nonresident African American fathers in our study. Both studies show that African American fathers can be engaged in intervention research. Findings from the Fathers and Sons Program further suggest the importance of involving the father and child to reinforce parent skill-building with males.

An important issue emphasized throughout the Father and Sons Program was the concept of fathers as role models for their sons based on SCT. Because sons can learn cognitions for drinking and actual drinking behaviors through observing their fathers' behavior, we assessed information about the fathers' drinking behavior. Intervention group fathers expressed their intentions to stop or reduce their drinking and requested professional services to help them stop drinking more frequently than comparison group fathers. It is not clear what prompted these fathers to ask for help (e.g., role reversal activity focused on alcohol abuse, relationships with intervention facilitators or other fathers in intervention, motivation to please sons, etc.), but it is important to recognize that these fathers were willing to request help for a serious health problem.

Fathers who asked for help were given information about community resources and they were encouraged to contact the needed services. We were not able to follow-up with each father to determine if services were actually used or if the fathers were satisfied with any services received. Future efforts should determine what motivates and under what conditions nonresident African American fathers will actually use professional services for health problems. This will not only help them personally, but it will help them to fulfill their father role responsibilities. The Fathers and Sons Program restricted the enrollment of known substance abusers; therefore, the numbers in these analyses are small. Nevertheless, the willingness of nonresident African American fathers to ask for help for problems with their drinking is an important achievement. 
Sons in the Fathers and Sons Program showed an increase in their intentions to avoid violence, which is a critical proximal step toward preventing youth violent behaviors. Contrary to our expectations, however, there was no reduction in aggressive behaviors among intervention sons. Our assessment of physical fighting and hitting and kicking when mad favored the comparison group. These results were unexpected because of the inclusion of violence prevention in the intervention. Two explanations for these findings may be plausible. First, the intervention was not effective in reducing aggressive behavior among African American boys. Second, it is too soon to tell. Observer notes available for most intervention sessions show that violence was a prevalent intervention content theme. It was the second largest thematic category mentioned due, in part, to many families living in communities in which violence is prevalent. There was no difference in reports of community violence between the intervention and comparison groups. The posttest was taken at the end of the intervention and saliency could be an issue. That is, by bringing undesirable fighting behaviors to the attention of the sons through intervention discussions and reinforcements from fathers, they may recognize and report it more. Future research will need to test this idea of vigilance in reporting because we did not obtain this data. Long-term data will be needed to understand these findings.

Several study limitations must be mentioned to put study findings into a more meaningful context. A quasi-experimental design was used; therefore, nonresident father-son families were not randomly assigned to intervention and comparison groups. This approach was necessary in this initial study because of the difficulty in recruiting a comparison group. Our original waitlist strategy did not work because recruited families wanted to be part of the intervention program and study attrition would have been high. To avoid this problem, we expanded to include a neighboring city with similar characteristics on key demographic factors to identify comparison group families; therefore the two groups are not completely comparable. We included known differences as covariates in the ANCOVA analyses to statistically account for biases introduced due to attrition and recruiting some families from a different city. In addition, the issues of self-selection bias and social desirability cannot be ignored when interpreting study findings. A key issue is the potential threat to internal validity introduced because families self-selected into the intervention and were not randomly assignment. Willingness to participate in the intervention could have been a factor in the positive intervention effects found for both fathers and sons. It is important to note, however, that families in the comparison group also had a strong desire to participate in the intervention program. The desire to please, especially in responding to study questionnaires, could have been a problem since contact with intervention families lasted 2 months. Interestingly, one of the significant study outcomes, reducing sons' aggressive behaviors, did not favor intervention participants.

This preliminary study is limited to assessing posttest data obtained at the end of the intervention program so that only short-term effects have been assessed. Long-term follow-up data will be necessary to ensure stability and confidence in findings. Further, the results are based on modest effect sizes. This study is testing the initial results of an intervention aimed at a population that has not been the focus of much intervention research. Available studies of similar study populations either do not include effect sizes or the interventions examined are for fathers of young children. Small to medium effect sizes appear to be typical in intervention studies with fathers (DiIorio et al. 2006; Fagan and Stevenson 2002).

\section{Conclusions}

The Fathers and Sons intervention was successful in influencing several key factors thought to be protective against youth risky behaviors. Especially promising are findings that suggest that nonresident African American fathers can improve their parenting behaviors related to parental monitoring and communication about sex. These findings are reinforced by our results that show improvements in these areas for sons as well as fathers. Family service providers, health educators, social workers, psychologists, and community organizers, should consider incorporating ways in which nonresident African American fathers may monitor their children and provide developmentally appropriate sexual socialization in their planning efforts. We found that many nonresident African American fathers are willing and able to participate in a family intervention aimed at assisting their children. Effectively engaging them in the fight against persistent risky behaviors among youth prior to the onset of problem behaviors seems essential.

Acknowledgments This research was funded by the Centers for Disease Control and Prevention through Grant \#R06/CCR521580 to the first author. Partial support also was provided through the Community Foundation of Flint, MI. The authors would like to thank members of the Project's Steering Committee for their insightful and dedicated work on this project, Dr. Marc Zimmerman for his vision and support of this project, and the many fathers and sons who participated in many aspects of this study. MS\#2008-078 R.

\section{References}

Ajzen, I., \& Fishbein, M. (1980). Understanding attitudes and predicting social behavior. Englewood Cliffs, NJ: Prentice Hall. Alan Guttmacher Institute. (2006). Facts on American teens' sexual and reproductive health. New York: AGI. 
Bandura, A. (1977). Self-efficacy: Toward a unifying theory of behavior change. Psychological Review, 84, 191-215.

Blake, S. M., Simkin, L., Ledsky, R., Perkins, C., \& Calabrese, J. M. (2001). Effects of parent-child communications intervention on young adolescents' risk for early onset of sexual intercourse. Family Planning Perspectives, 33, 52-61.

Blum, R. W., Beuhring, T., Shew, M. L., Bearinger, L. H., Sieving, R. E., \& Resnick, M. D. (2000). The effects of race/ethnicity, income, and family structure on adolescent risky behaviors. American Journal of Public Health, 90, 1879-1884.

Bosworth, K., Espelage, D. L., \& Simon, T. R. (1999). Factors associated with bullying behavior in middle school students. Journal of Early Adolescence, 23, 341-362.

Bowman, P. J., \& Sanders, R. (1998). Unmarried African American fathers: A comparative life span analysis. Journal of Comparative Family Studies, 29, Special Issue: Comparative perspectives on Black family life, pp 39-56.

Braver, S. L., \& Griffin, W. A. (2000). Engaging fathers in the postdivorce family. Marriage and Family Review: Fatherhood: Research, Interventions and Policies, 29, 247-267.

Brody, G. H., Murry, V. M., Gerrard, M., Gibbons, F. X., Molgaard, V., McNair, L., et al. (2004). The strong African American families program: Translating research into prevention programming. Child Development, 75, 900-917.

Caldwell, C. H., Sellers, R. M., Bernat, D. H., \& Zimmerman, M. A. (2004a). Racial identity, parental support, and alcohol use in a sample of academically at-risk African American high school students. American Journal of Community Psychology, 34, 71-81.

Caldwell, C. H., Wright, J. C., Zimmerman, M. A., Walsemann, K. M., Williams, D., \& Isichei, P. A. C. (2004b). Enhancing adolescent health behaviors through strengthening non-resident father-son relationships: A model for intervention with African American families. Health Education Research: Theory and Practice, 19, 644-656.

Cohen, J. (1988). Statistical power analysis for the behavioral sciences (2nd ed.). Hillsdale, NJ: Erlbaum.

Coley, R. L., \& Medeiros, B. L. (2007). Reciprocal longitudinal relations between nonresident father involvement and adolescent delinquency. Child Development, 78, 132-147.

D’Amico, E. J., Neilands, T. B., \& Zanbarano, R. (2001). Power analysis for multivariate and repeated measures designs: A flexible approach using the SPSS MANOVA procedure. Behavior Research Methods, Instruments, \& Computers, 33, 479-484.

Dancy, B. L., Crittenden, K. S., \& Talashek, M. (2006). Mothers' effectiveness as HIV risk reduction educators for adolescent daughters. Journal of Health Care for the Poor and Underserved, 17, 218-239.

DeLamater, J., \& Friedrich, W. N. (2002). Human sexual development. The Journal of Sex Research, 39, 10-14.

DiIorio, C., McCarty, F., \& Denzmore, P. (2006a). An exploration of social cognitive theory mediators of father-son communication about sex. Journal of Pediatric Psychology, 31, 917-927.

DiIorio, C., et al. (2006b). Keeping' it R.E.A.L. results of a motheradolescent HIV prevention program. Nursing Research, 55, 43-51.

Dittus, P. J., Jaccard, J., \& Gordon, V. (1997). The impact of African American fathers on adolescent sexual behavior. Journal of Youth and Adolescence, 26, 445-465.

Fagan, J., \& Stevenson, H. C. (2002). An experimental study of an empowerment-based intervention for African American head start fathers. Family Relations, 51, 191-198.

Forehand, R., Miller, K. S., Dutra, R., \& Chance, M. W. (1997). Role of parenting in adolescent deviant behavior: Replication across and within two ethnic groups. Journal of Consulting \& Clinical Psychology, 65, 1036-1041.
Fox-Wasylyshyn, S. M., \& El-Masri, M. M. (2005). Focus on research methods: Handling missing data in self-report measures. Research in Nursing \& Health, 28, 488-494.

Griffin, K. W., Botvin, G. L., Scheier, L. M., Diaz, T., \& Miller, N. L. (2000). Parenting practices as predictors of substance use, delinquency, and aggression among urban minority youth: Moderating effects of family structure and gender. Psychology of Addictive Behaviors, 14, 174-184.

Harrison, A. O., Wilson, M. N., Pine, C. H., Chan, S. Q., \& Buriel, R. (1990). Family ecologies of ethnic minority children. Child Development, 61, 347-362.

Haugaard, J. J. (2001). Problematic behaviors during adolescence. New York: McGraw Hill Publishers.

HEART of OKC Website. (2002). Reducing teen pregnancy in Oklahoma: Focusing on older teens (18-19 years old). The Healthy, Empowered and Responsible Teens of Oklahoma City (HEART OKC). http://www.health.state.ok.us/program/hpromo/medj/ oteens.html.

Henry, D. B., Tolan, P. H., \& Gorman-Smith, D. (2001). Longitudinal family and peer group effects on violence and nonviolent delinquency. Journal of Clinical Child Psychology, 30, 172-186.

Herrenkohl, T. I., Guo, J., Kosterman, R., Hawkins, J. D., Catalano, R. F., \& Smith, B. H. (2001). Early adolescent predictors of youth violence as mediators of childhood risks. Journal of Early Adolescence, 21, 447-469.

Hughes, D., \& Chen, L. (1997). When and what parents tell children about race: An examination of race-related socialization among African American families. Applied Developmental Science, 1, 200-214.

Israel, B. A., Eng, E., Schulz, A. J., \& Parker, E. A. (Eds.). (2005). Methods in community-based participatory research for health. San Francisco, CA: Josey-Bass.

Israel, B. A., \& Round, K. A. (1987). Social networks and social support: A synthesis for health educators. Advances on Health Education and Promotion, 2, 311-351.

Jacobson, K. C., \& Crockett, L. J. (2000). Parental monitoring and adolescent adjustment: An ecological perspective. Journal of Research on Adolescence, 10, 65-97.

Joshi, N. P., \& Battle, S. F. (1990). Adolescent fathers: An approach for intervention. Journal of Health and Social Policy, 1, 17-33.

Kirby, D., \& Miller, B. (2002). Interventions designed to promote parent-teen communication about sexuality. New Directions for Child \& Adolescent Development, 97, 93-110.

Kosterman, R., Graham, J. W., Hawkins, J. D., Catalano, R. E., Herrenkohl, T. I., \& Todd, I. (2001). Childhood risk factors for persistence of violence in the transition to adulthood: A social development perspective. Violence \& Victims: Special Issue: Developmental Perspectives on Violence and Victimization, 16, 355-369.

Kumpfer, K. L., Alvarudo, R., Smith, P., \& Bellany, N. (2002). Cultural sensitivity and adaptation in family-based prevention interventions. Prevention Science, 3, 241-246.

Lefkowitz, E., Sigman, S., \& Au, T. K. (2000). Helping mothers discuss sexuality and AIDS with adolescents. Child Development, 71, 1383-1394.

Li, X., Feligelman, S., \& Stanton, B. (2000). Perceived parental monitoring and health risky behaviors among urban low-income African American children and adolescents. Journal of Adolescent Health, 27, 43-48.

Martin, P. (2000). The African American church and African American parents: Examining relationships between racial socialization practices and racial identity attitudes. Unpublished Dissertation, Michigan State University.

Montano, D. E., Kasprzyk, D., \& Taplin, S. H. (1997). The theory of reasoned action and the theory of planned behavior. In K. Glanz, 
F. M. Lewis, \& B. K. Rimer (Eds.), Health behavior and health education: Theory, research and practice (2nd ed., pp. 85-112). San Francisco: Jossey-Bass Publishers.

Moore, K. A., Peterson, J. L., \& Furstenberg, F. F. (1986). Parental attitudes and the occurrence of early sexual activity. Journal of Marriage and the Family, 48, 777-782.

Nolin, M. J., \& Peterson, K. K. (1992). Gender differences in parentchild communication about sexuality: An exploratory study. Journal of Adolescent Research, 7, 59-79.

Paschall, M. J., \& Hubbard, M. L. (1998). Effects of neighborhood and family stressors on African American male adolescents' self-worth and propensity for violent behavior. Journal of Consulting and Clinical Psychology, 66, 825-831.

Potts, R. (2003). Emancipatory education versus school-based prevention in African American communities. American Journal of Community Psychology, 31, 173.

Seaton, E. K., Caldwell, C. H., Sellers, R. M., \& Jackson, J. S. (2008). The prevalence of perceived discrimination among African American and Caribbean black youth. Developmental Psychology, 44, 1288-1297.

Sellers, R. M., Copeland-Linder, N., Martin, P. P., \& Lewis, L. R. (2006). Racial identity matters: The relationship between racial discrimination and psychological functioning in African American adolescents. Journal of Research on Adolescence, 16, 187-216.

Sellers, R. M., Rowley, S. A. J., Chavous, T. M., Shelton, J. N., \& Smith, M. A. (1998). Multidimensional inventory of black identity: A preliminary investigation of reliability and construct validity. Journal of Personality \& Social Psychology, 73, 805-815.

Thomas, G., Farrell, M. P., \& Barnes, G. M. (1996). The effects of single-mother families and nonresident fathers on delinquency and substance abuse in Black and White adolescents. Journal of Marriage and the Family, 58(4), 884-894.

Thornberry, T., Smith, C., \& Howard, G. (1997). Risk factors for teenage fatherhood. Journal of Marriage and the Family, 59, $505-522$.

Thornton, M., Chatters, L., Taylor, R., \& Allen, W. (1990). Sociodemographic and environmental correlates of racial socialization by Black parents. Child Development, 61, 401-409.

Thornton, T. N., Craft, C. A., Dahlberg, L. L., Lynch, B. S., \& Baer, K. (2002). Best practices of youth violence prevention: A sourcebook for community action. Atlanta, GA: Division of Violence Prevention, National Center for Injury Prevention and Control, Centers for Disease Control and Prevention.
Ullman, J., \& Bentler, P. (2003). Structural equation modeling. In I. B. Weiner, D. K. Freedheim, J. Schinka, et al. (Eds.), Research methods in psychology, volume \#2: Handbook of psychology (pp. 607-634). Hoboken, NJ: Wiley.

USDHHS. (2001). Youth violence: A report of the surgeon general. www.surgeongeneral.gov.

Walker-Barnes, C. J., \& Mason, C. A. (2001). Ethnic differences in the effect of parenting on gang involvement and gang delinquency: A longitudinal, hierarchical linear modeling perspective. Child Development, 72, 1814-1831.

Way, N., \& Gillman, D. A. (2000). Early adolescent girls' perceptions of their relationships with their fathers: A qualitative investigation. Journal of Early Adolescence, 20, 309-331.

Williams, D. R., Neighbors, H. W., \& Jackson, J. S. (2003). Racial/ ethnic discrimination and health: Findings from community studies. American Journal of Public Health, 93, 200-208.

Wills, T. A., Ainette, M., Mendoza, D., Gibbons, F. X., \& Brody, G. H. (2007). Self-control, symptomatology, and substance use precursors: Test of a theoretical model in a community sample of 9-year-old children. Psychology of Addictive Behaviors, 21, 205-215.

Wills, T. A., Gibbons, F. X., Gerrard, M., Murry, V. M., \& Brody, G. H. (2003). Family communication and religiosity related to substance use and sexual behavior in early adolescence: A test for pathways through self-control and prototype perceptions. Psychology of Addictive Behaviors, 17, 312-323.

Winters, K. C., \& Zenilman, J. M. (1994). Simple screening instruments for outreach for alcohol and other drug abuse and infectious diseases: Treatment improvement protocol (TIP) series. US Department of Health and Human Services, Public Health Service, Substance Abuse and Mental Health Services Administration, Center Substance Abuse Treatment.

Zimmerman, M. A., Salem, D. A., \& Notaro, P. C. (2000). Make room for daddy II: The positive effects of fathers' role in adolescent development. In R. Taylor \& L. Wang (Eds.), Resilience across contexts: Family, work, culture, and community (pp. 233-253). Mahwah, NJ: Lawrence Erlbaum Associates Inc.

Zimmerman, M. A., Steinman, K., \& Rowe, K. (1998). Violence among urban African American adolescents: The protective effects of parent support. In S. Oskamp \& B. Arriaga (Eds.), Addressing community problems: Research and intervention (pp. 78-103). Newbury Park, CA: Sage. 